\title{
A comparison between Chinese and Australia background students' performance in NMIT
}

\author{
Zonghan Yang ${ }^{1, a}$, Con Nikakis ${ }^{2, b}$, Lin Tang ${ }^{1, c}$ \\ ${ }^{1}$ Guilin University of Aerospace Technology, Guilin 541004, China \\ ${ }^{2}$ Northern Melbourne Institute of TAFF, Melbourne 32 State VIC32, Australia \\ ayanghan77777@163.com, bconnikakis@nmit.edu.au, ctanglin@guat.edu.cn
}

Keywords: academic performance; cultural background; aims of study; age.

\begin{abstract}
The purpose of current research is to determine whether there is difference between Chinese and Australia background students' academic performance. Furthermore, we apply the analysis of variance to see if there is any difference between the academic performances of different student groups on some variables. These variables include students' cultural background, age, and the aims of study. The result of current research is that there is not enough evidence indicating that the variables, students' cultural background and age, have effect on the students' academic performance. In addition we find that students' aims for study have significant effect on the students' academic performance. With the development of Chinese economy more and more Chinese students travel to Australia for higher education. Current research gives an insight into Chinese and Australia background students' academic performance.
\end{abstract}

\section{Introduction}

\subsection{The Data Collection}

This study was conducted in the Department of Higher Education Business at Northern Melbourne Institution of TAFE (NMIT). Data for current research were extracted from the student records system. All subject records taught during spring 2012 and spring 2013 were identified and extract in a temporary table.

\subsection{Attributions for Students' Performance}

Current research attempts make some contribution to the confusing area that what factors impact thje students' academic performance, in particular, focuses on the difference between the Australia background and the Chinese background students' academic performance in Australia higher education sector.

\subsection{The Assessment of Students' Performance}

There are all kinds of approaches to assess the students' performance. These approaches usually include questionnaire investigation and the using of subject grades. In current research, to assess the students' academic performance, we use the final grade of specific subjects in several semesters.

\section{4 Research Problems}

Based on the previous researches and the current research conditions, several key research problems are proposed.

Is there statistically significant difference in academic performance of the students with Chinese background comparing to the students with Australia background;

Is students' academic performance related to the students' cultural background;

Is students' academic performance related to the students' age;

Is students' academic performance related to the students' aim for study;

Is there any significant difference in students' academic performance when we take the students' cultural background and the students' age acting together;

Is there any significant difference in students' academic performance when we take the students' cultural background and the students' aims for study acting together. 


\section{Research Methods}

The population for the current research was the student subject records for students enrolled in all courses taught between spring 2012 and spring 2013. The sample of current research was chosen in stage. At the first stage, we divided the student subject records into several primary sample units according to the subject name. At the second stage, three primary sample units were chosen. These primary sample units included the subject records of Management Principles (BACC108), the subject records of World Business Environment (BUS101) and the subject records of Macroeconomics (BACC201). At the third stage, each of the three primary sample units were divided into Chinese background students' records, Australia background students' records.

\section{Empirical Result}

\section{1 Descriptive Analysis and Statistic}

According to our descriptive analysis and statistic, the distribution of research sample is reasonable, it contributed to the current study.

\section{2 Two Samples T-test}

Chinese background students' sample mean of 40.16 ( $\mathrm{SD}=26.25)$ was significantly lower than Australia background students' sample mean of $48.94(\mathrm{t}(\mathrm{df128})=2.1, \mathrm{p}<0.05)$. Since $\mathrm{p}$-value $=$ $0.038<0.05$, at $\alpha=0.05$ level of significant, there was no enough evidence to conclude that the students' mean final grades were the same for two student groups with different cultural background.

\section{3 Analysis of Variance}

Three one-way analys of variance were conducted by SPSS, the result from the analysis (table $1,2,3$ ) indicated that the students' cultural background, age and aim for study did not has significant effect on the students' academic performance.

Table 1 One-way analysis of variance of cultural background

\begin{tabular}{cccccc}
\hline Culture & \multicolumn{5}{c}{ ANOVA } \\
\hline & Sum of Squares & Df & Mean Square & F & Sig. \\
\cline { 2 - 6 } Between Groups & 158.209 & 1 & 158.209 & 1.466 & 0.293 \\
Within Groups & 431.815 & 4 & 107.954 & & \\
Total & 590.024 & 5 & & & \\
\hline
\end{tabular}

Table 2 One-way analysis of variance of age

\begin{tabular}{cccccc}
\hline Age & \multicolumn{5}{c}{ ANOVA } \\
\hline & Sum of Squares & Df & Mean Square & F & Sig. \\
\cline { 2 - 6 } Between Groups & 164.929 & 2 & 82.465 & 0.863 & 0.468 \\
Within Groups & 573.135 & 6 & 95.522 & & \\
Total & 738.064 & 8 & & & \\
\hline
\end{tabular}

Table 3 One-way analysis of variance of students' aim for study

\begin{tabular}{cccccc}
\hline Aim for Study & \multicolumn{5}{c}{ ANOVA } \\
\cline { 2 - 5 } Between Groups & Sum of Squares & df & Mean Square & F & Sig. \\
\cline { 2 - 5 } Within Groups & 1004.61 & 2 & 502.305 & 6.509 & 0.031 \\
Total & 463.016 & 6 & 77.169 & & \\
\hline
\end{tabular}

Two two-way analys of variance were conducted by SPSS to determine the relationship between the independent variables. From the analysis of table 4, it indicated that the Culture*Age interaction was also not significant, $F(2,12)=0.27, \mathrm{p}$-value $=0.768>0.05$. Table 5 indicated that the Culture*Aim interaction was also not significant, $\mathrm{F}(2,12)=0.417$, p-value $=0.668>0.05$. 
Table 4 Two-way analysis of variance of students' age

\begin{tabular}{cccccc}
\hline \multicolumn{2}{c}{ Dependent variable: Culture \& Age } & \multicolumn{5}{c}{ Tests of Between-Subjects Effects } \\
\hline Source & of Squares & df & Mean Square & F & Sig. \\
\hline Corrected Model & $824.926 \mathrm{a}$ & 5 & 164.985 & 0.852 & 0.54 \\
Intercept & 35169.283 & 1 & 35169.283 & 181.511 & 0 \\
Culture & 515.752 & 1 & 515.752 & 2.662 & 0.129 \\
Age & 204.373 & 2 & 102.187 & 0.527 & 0.603 \\
Culture * Age & 104.801 & 2 & 52.4 & 0.27 & 0.768 \\
Error & 2325.095 & 12 & 193.758 & & \\
Total & 38319.304 & 18 & & & \\
Corrected Total & 3150.02 & 17 & & & \\
\multicolumn{2}{c}{ a R Squared } & $=.262$ (Adjusted R Squared $=-.046)$ & &
\end{tabular}

Table 5 Two-way analysis of variance of students' aim for study

\begin{tabular}{cccccc}
\hline \multicolumn{2}{c}{ Dependent Variable: Final Grade } & \multicolumn{3}{c}{ Tests of Between-Subjects Effects } \\
\hline Source & Type III Sum of Squares & df & Mean Square & F & Sig. \\
\hline Corrected Model & $886.969 \mathrm{a}$ & 5 & 177.394 & 0.348 & 0.874 \\
Intercept & 38545.208 & 1 & 38545.208 & 75.719 & 0 \\
Culture & 442.319 & 1 & 442.319 & 0.869 & 0.37 \\
Aim & 20.016 & 2 & 10.008 & 0.02 & 0.981 \\
Culture *Aim & 424.634 & 2 & 212.317 & 0.417 & 0.668 \\
Error & 6108.69 & 12 & 509.058 & & \\
Total & 45540.867 & 18 & & & \\
Corrected Total & 6995.66 & 17 & & \\
& a R Squared $=.127$ (Adjusted R Squared = -.237) &
\end{tabular}

\section{Discussion}

John Cresswell's report (2004) supported by Australia Council of Education Research has found that students whose home language is English performed better in reading and scientific literacy than those whose home language is non-English. But in current study, we did not find that the students' cultural background had effects on the students' academic performance in NMIT higher education sector.

There have been some limitations to current research. At first, there might be other attributions to be considered in the exploration of students' academic performance. Inclusion of more attributions is more likely to improve the explaining power of current research. Secondly, the sample size is relative small so that we cannot conduct an analysis of variance with more levels. Thirdly, the current research focuses on NMIT and its students only. It is necessary to investigate the same issue across different institutes and student groups for improving the explaining power of our research.

\section{References}

[1]Arumugam N, Rafik-Galea S, Mello G d, Dass L C. Cultural Influences on Group Learning in an ESL Classroom[J]. Review of European Studies, 2013 (2): 81-89.

[2]Atchley $\mathrm{T}$ W, Wingenbach G, Akers C. Comparison of course completion and student performance through online and traditional courses[J]. The International Review of Research in Open and Distance Learning, 2013 (4): 104-116.

[3]Davies J. A Preliminary Investigation into the Major Concerns of Chinese Students Preparing to Study Abroad: A Practical Approach to Facilitating Student Transition[J]. English Teaching in China, 2013 (2): 8-12. 
[4]Dee T S, Jacob B. The impact of no Child Left Behind on student achievement[J]. Journal of Policy Analysis and Management, 2011 (3): 418-446.

[5]Friedkin N E, Necochea J. School system size and performance: A contingency perspective[J]. Educational Evaluation and Policy Analysis, 1988 (3): 237-249.

[6]Ge L, Thomas S. A cross-cultural comparison of the deliberative reasoning of Canadian and Chinese accounting students[J]. Journal of Business Ethics, 2008 (1): 189-211.

[6]Hing H, Sit W. Characteristics of Chinese Students' Learning Styles[J]. International Proceedings of Economics Development and Research, 2013 (8): 36-39.

[7]McComas J J, Raghallaigh M O. Introduction to the Special Issue: The Influence of Cultural and Linguistic Variables on Student Behavior and Academic Performance[J]. jornal of behavior education, 2011: 221-223.

[8]Moodie G, Wheelahan L. The significance of Australian vocational education institutions in opening access to higher education[J]. Higher Education Quarterly, 2009 (4): 356-370.

[9]Paul C W, Ruhland J S. A Note On Job Market Conditions And Students' Academic Performance[J]. Journal of Business \& Economics Research 2013 (5). 